\title{
Electric Motors for Variable-Speed Drive of Lock Valves
}

\author{
Aleksey V. Udovichenko ${ }^{1, *}$, Dmitri Kaluzhskij ${ }^{1}$, Nikita Uvarov ${ }^{1}$ and Ali Mekhtiyev ${ }^{2}$ \\ 1 Electrical Engineering Department, Novosibirsk State Technical University, Novosibirsk, Russia, E-mail: \\ alevud@gmail.com, kaluzhskij@corp.nstu.ru, uvarov.nik.64@gmail.com \\ 2 Seifullin Kazakh Agrotechnical University, Nur-Sultan, E-mail: barton.kz@mail.ru \\ * Correspondence: alevud@gmail.com
}

\begin{abstract}
Improving the operational reliability of nuclear power plants, combined heat and power plants (CHP), as well as oil and gas pipelines is a priority task in the development of a variablespeed drive for lock valves used at these facilities. The paper analyzes technical requirements for such devices; the motor has been selected, its electrical equilibrium and moment equations have been obtained; recommendations for the selection of the kinematic drive scheme have been formulated. Based on the theoretical data obtained, a prototype has been developed, manufactured and tested.
\end{abstract}

Keywords: Lock valve, motor with electromagnetically reduction of speed, permanent magnet, stress and moment equations, electric drive

\section{Introduction}

Developing, designing and producing adjustable lock valves play an important role in ensuring human life. Thus, the annual global demand for valves of only one type, highpressure steam with setup diameters from 20 to $350 \mathrm{~mm}$ used at nuclear power facilities and heat and power plants, amounts to tens million pieces per year, and the cost of some samples can exceed \$50,000.

Various researchers have dealt with the design problems of new electrical machines with an increased starting torque. Work [1] presents a modified method of predicted torque control of induction machines. This method allows reducing the torque ripple at the moment of starting a highly loaded AC electric motor. The modified predictive torque control results in a more stable starting behavior of the electric motor in relation to torque ripple control methods compared to conventional direct torque control. Field control (FOC) and direct torque control (DTC) methods are reported to be the two most commonly used control methods for induction machine (IM) drives operating under severe starting conditions. But the data for the method are already technically outdated enough $[2,3]$. DTC and FOC methods associated with direct self-control of the starting torque were introduced into the industry at the end of the 80s of the last century [4-6]. Commercial use in manufacturing lock valve drives was developed in the mid-90s of the last century [7]. The presented methods did not allow ensuring completely the stable operation of the electric motor in the low-speed range, and did not allow getting rid completely of the torque ripples at the start. There are also known methods of variable load control and space-vector modulation (SVM), which provide more stable operation of an AC motor at low speed discussed in [8]. Improvements to the DTC method can be found in [9], but even all the improvements do not allow controlling efficiently the lock 
valve drive without the use of a gearbox. In parallel with the methods considered above, MPC methods based on the use of power electronics were developed. They are considered in works [10-14]. There are various options of the MPC implementation, for example, FCSMPC used for motor start control, but it requires significant computational power of the control system due to the fact that it is necessary to calculate the weighting factors for all possible transients. Many researchers have improved this method with a combination of modern control methods to increase the MPC reliability [15-17]. It also provides the information of the empirical procedure for obtaining suitable weighting factors [18]. Direct use of the considered methods is impossible to control the drive without a gear valve, since at the start it is possible that the stem will be stationary due to the slagging of the cone. In this situation, the current protection must be triggered in order to prevent the failure of the electric motor. The value of the phase current should change in a small range in all the operating modes of the electric drive, from idle to short circuit. It is also desirable to remove the current and thermal protection from the electric circuit of the drive and not to introduce into the control system a time limit for working out a given movement. This requires a different drive control principle and a completely different design. So in [19] there is the information of induction machines that have a strongly nonlinear characteristic; it also presents the results of research carried out on a $50 \mathrm{HP}$ asynchronous motor driven by a three-phase inverter, which provides high-quality speed and torque control. The IM torque control IM using FOC has been considered quite often in past studies; in [20] various methods of slip control are presented for different modes of starting an electric motor at different loads. There is also the information of the adaptive control of the sliding mode [21]. Work [17] proposes simplified models for convenient fixation of transient processes of an AC electric motor, which can be used in the design of induction machines, but this model is rather simplified and has lost its relevance at the present time [22]. There are studies presented in [23] related to duty cycle modulation, direct torque control, brushless machines with double feed. For brushless double feed machine (BDFM), traditional direct torque control (DTC) has many problems such as a large output torque ripple and undefined inverter switching frequency. The presented control method has several advantages over traditional direct torque control, while reducing the ripple flux linkage. There are also proposed measures to optimize direct torque control. The SVM - DTC algorithm [4] can effectively reduce the torque ripple, but it requires large calculations and additional parameters, which cannot be used for lock valves due to the increased cost of the control system. There is some information of the methods of monitoring the magnetic fields of permanent magnet synchronous machines using a Texas Instruments F28343 $200 \mathrm{MHz}$ microcontroller [25]. There are similar works related to the regulation of electric machines with permanent magnets, which provide an algorithm for finding the optimal current vector [26], analytical solutions [27] and the search for methods to minimize losses [28, 29]. There are research results in the aspect close to this work, where the reversible dependence of the speed and the time of an asynchronous machine at start-up without load and with load is considered, based on the induction parameters. There is presented an equivalent circuit of the machine and a description of the torque equation method. Analytical expressions of the speed 
dependence on the time of an asynchronous machine with a direct start are considered. The process of starting an electric motor with a large starting torque is a rather serious scientific and practical problem [31,32]. IM starting methods are based on the use of soft starters [33] or by shunting the stator and rotor windings, which are quite outdated [34], as well as on the use of power electronic devices [35]. In work [36], there is presented the calculation of the permanent magnet synchronous machine parameters, taking into account characteristics of the load.

Let's list the main requirements that must be taken into account when designing drives for lock valves [37]:

- a high degree of protection from the environment. As a rule, motors and control systems are designed with protection not less than IP54 (closed, protected design allowing the presence of water jets at any point on the outer surface of a technical object);

- significant excess of the maximum torque at start, in comparison with the nominal value with free movement of the stem. So, examining a high-pressure steam valve with a setup diameter of $20 \mathrm{~mm}$, it was found that in the nominal mode, the torque of 5-10 Nm is required (depending on the equipment wear), and when the "slagged" stem is torn off in the closed state, the torque increases to $80 \mathrm{Nm}$;

- low speed of the drive output shaft at the level of $10-20 \mathrm{rpm}$, which should exclude the possibility of hydrodynamic shock. Therefore, in drives that do not provide for speed variation and operating in the "start-stop" mode, it is necessary to use gearboxes with a large gear ratio. Traditionally, in such valves, asynchronous motors are most often used. They are designed for an output shaft speed of 1000 and $1500 \mathrm{rpm}$. Therefore, for them, the minimum value of the reduction factor is 50 units, and this is a rather complex and expensive technical object;

- there are practically no requirements regarding the limitations of the dimensions and weight of the electric actuator of lock valves;

- difficult access to many objects of the lock valves. This feature is most significantly manifested in heating plants, as well as in the areas of oil and gas pipelines remote from settlements;

- $\quad$ high reliability of protection of motor windings from overheating and maximum permissible currents.

The analysis of the above-mentioned data inevitably leads to the need of solving the problem in which two mutually exclusive requirements are laid: the first one is taking into account the peculiarities of operation. It is necessary to simplify the control system as much as possible, since the elements of power electronics are most susceptible to the effect of the environment and are the "weak link" of the entire drive. The second one consists in that if you design a drive that does not include the possibility of speed regulation, then in the starting mode the current in the windings will increase 5 - 8 times. This means that if within a short time interval the torque on the shaft does not decrease to the nominal value, the current protection must be triggered. In such a situation, when there is not enough time to start the movement of the stem, there is a need for repeated (or multiple) switching on the drive, and, in extreme cases, the use of human physical strength [38-40]. 
Thus, the ideal solution to this problem is the use a motor in the drive with the following characteristics:

- when connected to an industrial network of alternating current $50 \mathrm{~Hz}$ (or $60 \mathrm{~Hz}$ ), the shaft rotation frequency will be $10-120 \mathrm{rpm}$, which will either get rid of the gearbox in the drive kinematic diagram, or eliminate the problem of developing a complex mechanical transmission;

- the value of the specific moment (the ratio of the moment to the mass of the drive) is comparable to that of a drive containing an asynchronous motor and a gearbox [41];

- there are no moving contacts due to the presence of a collector, slip rings, etc. This condition is most significant when it comes to the explosion-proof version of the drive;

- the value of the phase current varies in a small range for all modes of operation, from no-load to short-circuit. If this condition is met, then it becomes possible to remove the current and thermal protection from the drive and not to introduce into the control system a time limit for the specified movement.

This set of requirements is most satisfied by inductor motors with electromagnetic speed reduction. For example, if we take an inductor machine with a distributed winding on the stator and a ring magnet on the rotor, then the excitation field for it will be determined as

$$
B_{m 1}=\beta B_{m 0} \cos \left(z_{2} \theta-v \alpha\right)
$$

where $B_{m 0}$ is the constant component of magnetic induction due to the flow of magnets; $\beta=0.4-0.6$ is the coefficient of the magnetic conductivity of the air gap pulsation; $z_{2}$ is the number of rotor teeth; $v$ is the number of periods of changing magnetic conductivity equal to the number of pole pairs $p=v ; \alpha$ is the angle along the inner surface of the

stator; $\theta=\int_{0}^{t} \omega_{p} d t+\theta_{0}$ is the angle of rotation of the rotor; $\omega_{p}$ is the angular frequency of rotation. In the linear formulation of the problem, substituting (1) into the energy equation and differentiating the result by the angle of rotation of the rotor, we obtain the expression for the moment

$$
M_{\text {эм1 } 1}=0,25 z_{2} \beta \pi D_{a} l_{a} B_{m 0} F_{m 1} \times \sin \left(z_{2} \theta_{0}\right) .
$$

Here: $D_{a}, l_{a}$ is the stator inner diameter and active length; $\theta_{0}$ is the initial value of the angle of rotation of the rotor. The number of rotor teeth and the number of pole pairs in an inductor machine with axial excitation, having an electromagnetic speed reduction, is related by the ratio:

$$
z_{2}=2 m p q \pm p=p(2 m q \pm 1)
$$

Then the ratio of the maximum moments of an inductor machine with an axial flux and a classical synchronous machine with permanent magnets on the rotor with 
unchanged dimensions, electrical losses, the number of pole pairs and the current density will be equal to:

$$
M_{э м 11} / M_{\ni м 1}=\beta(2 m q \pm 1) \approx 2,0-4,2^{\prime}
$$

which is in complete agreement with earlier estimates, for example, in [42, 43].

Now let us compare the capabilities of two inductor machines with excitation from ring permanent magnets, provided that one of the machines has a distributed winding on the stator, and the other one has a winding with a toothed pitch [44, 45]. To simplify the analysis, we represent the excitation field and MMF in the form of idealized discrete Rademacher functions, as it was done in [42]. If we do not touch upon the design features of the magnetic system and assume that the fundamental harmonic of the field is the same as in the previously considered cases, then:

$$
M_{\text {วм22 }}=\frac{z_{2} \beta \pi D_{a} l_{a} B_{m 0} F_{m 21} z_{s}}{4\left(z_{s}+k\right)} \times \sin \left(z_{2} \theta_{0}\right)
$$

Here $z_{s}$ is the number of elementary teeth located on the inner surface of the large teeth, in the grooves between which the winding is laid; $k=0,1,2$ is the difference between the maximum possible and accepted in the design of the $z_{s}$ value.

Using the previously obtained expressions [46, 47], we find the ratio of the moments of an inductor motor with a distributed winding on rotor and a synchronous machine with permanent magnets on the rotor:

$$
M_{\ni . M 22} / M_{\text {э.1 }}=\frac{12 \beta z_{s}}{\pi\left(z_{s}+k\right)} \times\left[\left(z_{s}+k\right) \pm \frac{1}{2 p \pm v}\right] \approx \frac{12 \beta}{\pi} \times z_{s}^{\prime}
$$

where $z_{s}$, based on the recommendations for selecting the geometry of the notchedgroove zone [48], takes values from three to six. Thus, in the linear formulation of the problem, the torque of the inductor motor is $(4.6$ - 6) times higher than that of a synchronous machine with magnets! This gives grounds to assert that the proposed engine has solid technical advantages over other types of electrical machines and can be considered as the basic option when designing a lock valve drive with a coaxial planetary gear.

\section{Mathematical model}

The most famous representative of electric machines with an axial flow is a twophase stepper motor with electromagnetic speed reduction made according to [45]. The motor contains a toothed two-pack rotor and a stator. An annular magnet is located between the packages of the rotor and produces a unipolar magnetic flux within each half of the machine. There are eight large teeth on the stator, on the inner surface of which there are elementary teeth with a toothed division close to or equal to the tooth division on the rotor. The coils belonging to phase A are placed on large stator teeth, the geometric angle between which is 90 degrees. The other 4 teeth with coils belong to phase B. 
If positive voltage is applied to phase $\mathrm{A}$, then under two diametrically located large teeth, the unipolar field is enhanced, and under large teeth that are offset by the angle of 90 degrees, it is weakened. With an appropriate selection of the number of elementary teeth on the stator and rotor $z_{1}$ and $z_{2}$, the rotating part of the electric machine is magnetically an elliptical ferromagnetic blank. Such a "rotor" will always strive to take such a position that the minimum air gap is in the area where the magnetic field is maximum. When the voltage polarity on phase A changes, the "rotor" will rotate 90 electrical degrees or by $t_{z 2} / 4$. The development of intermediate positions that are multiple to $t_{z 2} / 8 \mathrm{~s}$ is carried out by disconnecting phase $\mathrm{A}$ from the power source and the corresponding switching in phase B.

In the considered design, several negative factors can be distinguished.

1. To develop a large unipolar flux, it is necessary to increase to the limit the ratio of the bore diameter to the inner diameter of the rotor. Otherwise, it is necessary to reduce the length of each stator (rotor) package or to develop a multi-package structure. However, such a step will entail relative increasing the non-working zones (between packets) and, as a consequence, decreasing the specific moment.

2. To close the unipolar flux along the stator, a massive ferromagnetic housing is required. (To eliminate this negative factor, the French company SAGEM makes the stator packages not lined but limits the maximum rotational speed to 18 - $20 \mathrm{rpm}$ ).

3. With a small cross-section of the groove, it is impossible to develop armature flux of the required magnitude, since it closes along a long path (a quarter of the circumference) with high magnetic resistance. Additional decreasing is due to the branching of magnetic field lines in the area where there are no currents $(2,4,6,8$ - Figure 1), which is clearly demonstrated by the problem of graphic - analytical calculation of the field.

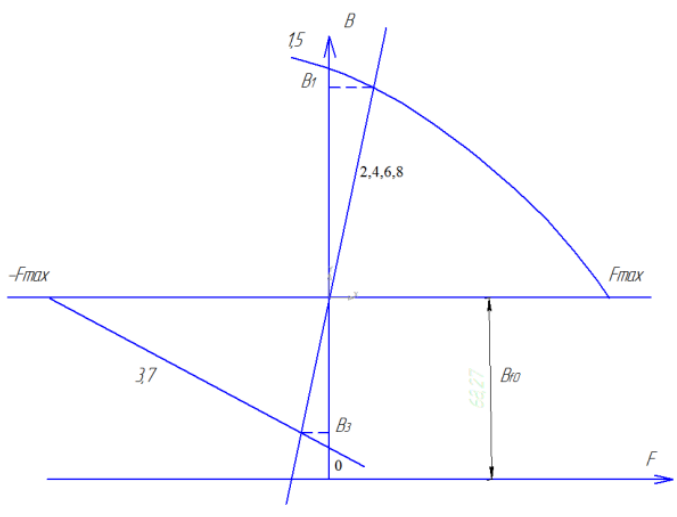

Figure 1. Graphic-analytical calculation of the field.

To eliminate the indicated drawbacks in the motor for the drive of lock valves, it is necessary to: a) place permanent magnets that develop a radial flow on the stator; $b$ ) combine the coils belonging to the same phase on magnetically isolated segments. The set tasks are fully solved in the design of the electric motor made according to [49] (see Figure 2). Here the stator package is divided into $2 \mathrm{mk}(\mathrm{k}=1,2,3, \ldots$ is an integer) of segments, 
each of which has large teeth with coils belonging to the same phase. The coils are in aiding connection in order to reinforce mutually each other's magnetic fluxes. Permanent magnets are located between the segments developing a radial field of excitation of the same polarity within the segment. Thus, if one coil amplifies, the other weakens the resulting field.

In contrast to the two-phase analogue considered above, here, due to the magnetic isolation of the segments, the armature field is weakened only due to the scattering fluxes and, as calculations show, it turns out to be 10-15\% greater than the field under the large teeth 1, 5 (Figure 3 ). Another positive feature of the motor is that the excitation flow and the armature flow are closed in different parts by a yoke and come together only in the "right places": the air gap and the large tooth. For example, the excitation flux from the top magnet in Figure 4 closes along large teeth 1, 12 and the areas with a yoke between them, and the anchor flow closes only along large teeth 1,2 and the areas with a yoke between them. This allows minimizing the height of the rotor yoke and designing the motor with a large internal bore in the shaft required for the valve stem to pass.

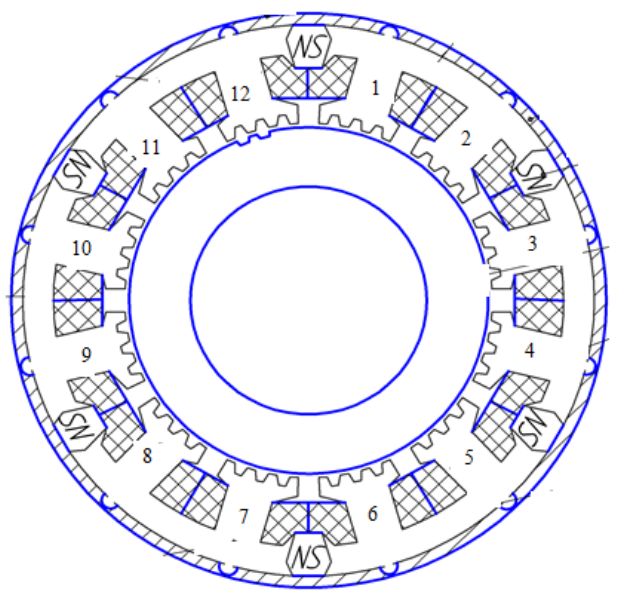

Figure 2. Electric motor design

It is also important that there is no unipolar flux (magnetic circuit) in the machine under consideration, which greatly simplifies the design of the motor. We also note the main feature of the proposed technical solution: the absence of a rotating magnetic field, which at first glance contradicts the fundamental provisions of the general theory of electrical machines. This "paradox" is explained as follows. Let's select in the motor large teeth (segments), within which the field of excitation has the same direction: 1, 2 - phase A; 5, 6- phase C; 9, 10 - phase B. Suppose that with a fixed position of the rotor, magnetic conductivity of the air gap within each large tooth is determined as shown in Figure 3 and is provided with a different distance between adjacent elementary teeth located on different large teeth. In this case, it can be assumed that within each large tooth, "its own rotor" rotates with the $z_{2} \omega_{p}$ frequency. It presents a ferromagnetic segment located with the eccentricity relative to the stator and having "its own initial phase". If we mentally cut 
such a machine into six parts and rearrange its individual fragments accordingly, then the mathematical analogue of a real motor will look as shown in Figure 4.

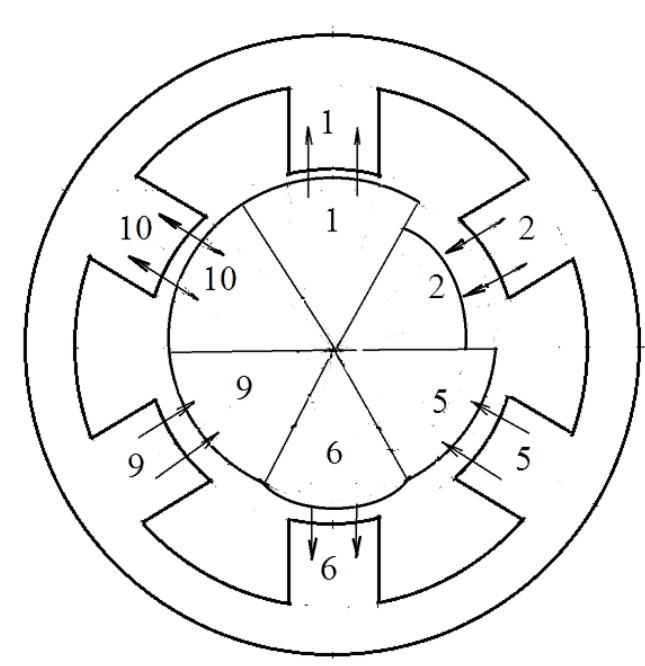

Figure 3

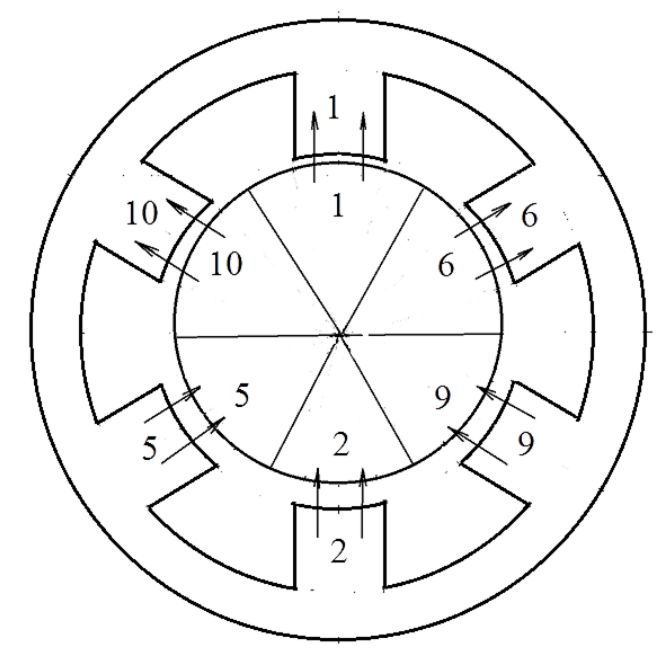

Figure 4

Air gap magnetic conductivity within each large tooth with a fixed rotor position

\section{Control algorithm}

Figure 5 shows a possible algorithm of controlling an electric drive using a voltage inverter (VI), in which the torque of the electric motor operating at maximum speed is regulated. The algorithm is based on the ideas of work [43].

To ensure the required ratio between the fundamental and higher time harmonics of the current, negative feedbacks on the motor currents are used. In this case, in the rotating coordinate system, a signal is set by the first and fifth harmonics, and the assignment for the 5 th harmonic is determined by the ratio

$$
\left\{\begin{array}{l}
i_{3 q 5}=i_{3 d} 0.19 \sin [6 \gamma(t)]+i_{3 q} 0.19 \cos [6 \gamma(t)], \\
i_{3 d 5}=i_{3 d} 0.19 \cos [6 \gamma(t)]-i_{3 q} 0.19 \sin [6 \gamma(t)]
\end{array}\right.
$$

where $i_{3 d}, i_{3 q}$ are signals for setting the orthogonal current components in the first harmonic; $\gamma(t)$ is the instantaneous value of the phase of the VI output voltage that is set using the rotor position sensor (RPS). 


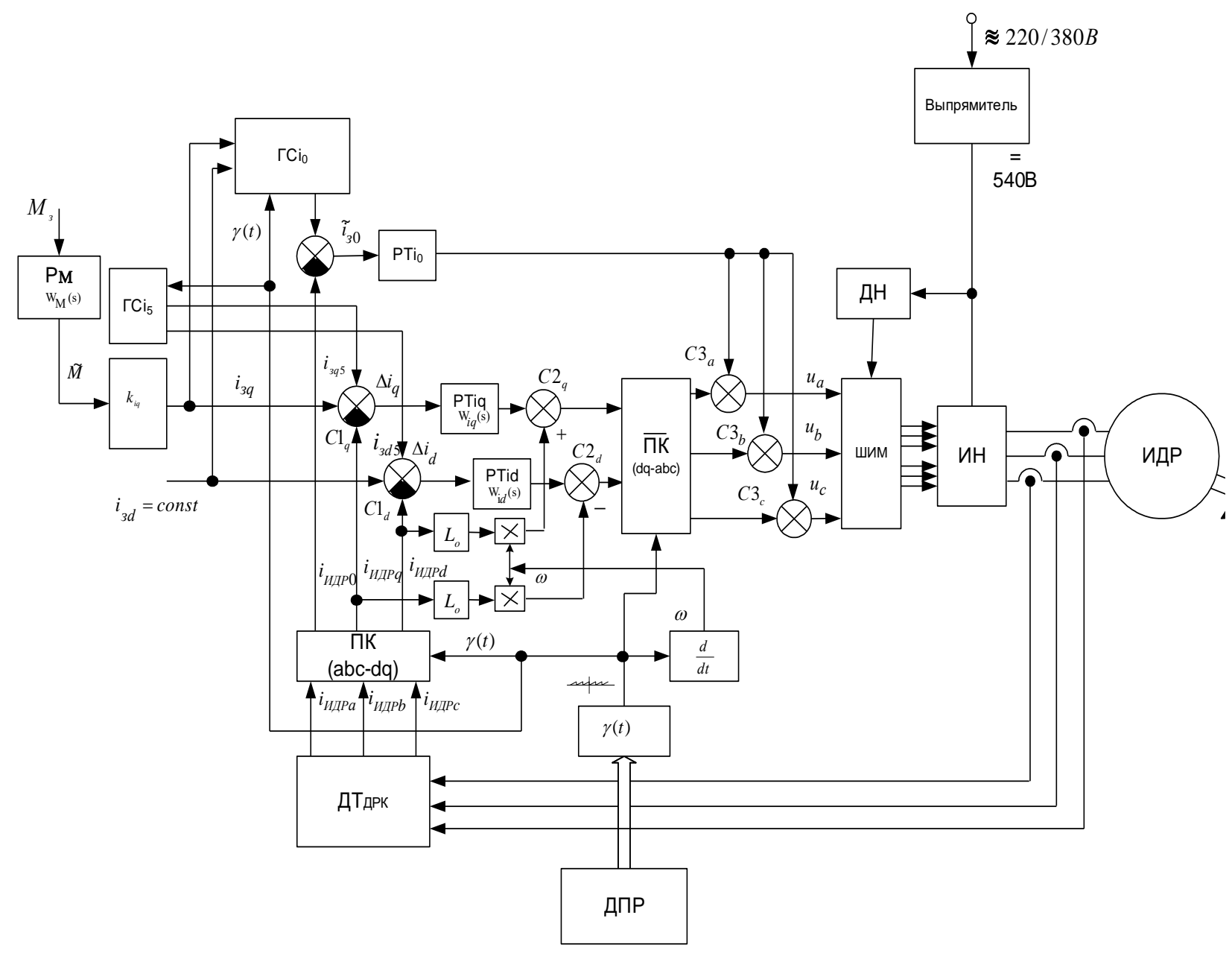

Figure 5. Algorithm of controlling an electric drive using a voltage inverter (VI)

The shape of the assignment total signals along the orthogonal axes is shown in Figure 6.

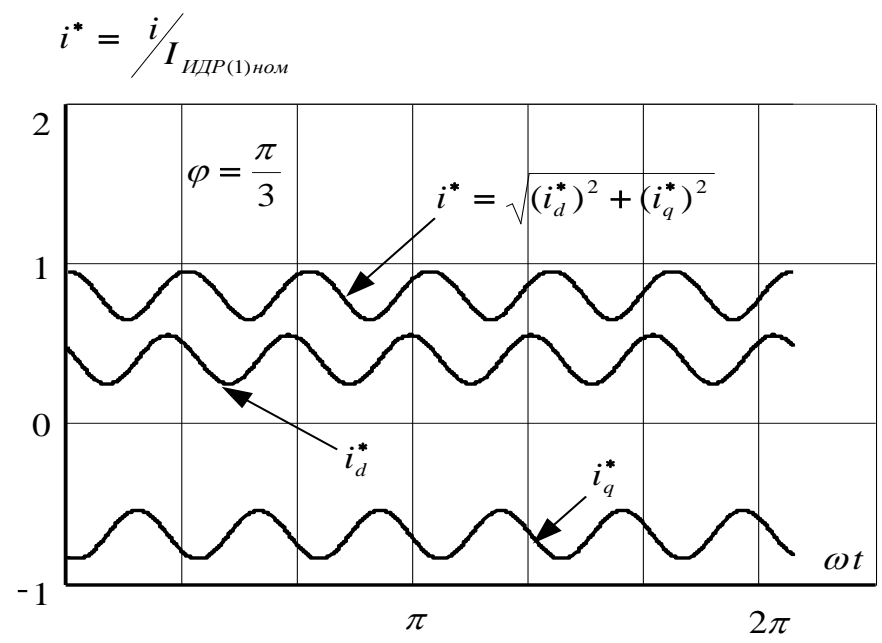

Figure 6 . The shape of the assignment total signals along the orthogonal axes Here 


$$
\left\{\begin{array}{l}
i_{q}=i_{3 q}+i_{3 q 5}, \\
i_{3 d}=i_{3 d}+i_{3 d 5} .
\end{array}\right.
$$

The signals of the third harmonic form a zero sequence and therefore are formed in the "A-B-C" axes according to the relation

$$
i_{30}=0.32\left\|i_{3}\right\| \sin \left[3 \gamma(t)-3 \varphi_{i}\right],
$$

where $\varphi_{i}=\operatorname{arctg}\left(i_{\text {зq }} / i_{\text {зд }}\right)$.

To obtain astatic regulation of the fundamental harmonic of the electric motor currents, PI controllers are used with transfer characteristics of the form:

$$
W_{i d}(s)=W_{i q}(s)=K_{I} / s+K_{\Pi}
$$

The transfer characteristic itself in the torque control channel (TR) in the general case has the form

$$
W_{M}(s)=\frac{b_{1} s+b_{0}}{a_{1} s+a_{0}} .
$$

In order to ensure the dependence of the orthogonal components of the electric motor current on the magnitude of the torque, the $k_{i q}(\tilde{M})$ and $k_{i d}(\tilde{M})$ links were introduced.

The nature of the dependence of these coefficients on the magnitude of the $\tilde{M}$ moment is shown in Figure 5.

As a result of using the proposed algorithms, the shape of the resulting current in the motor phases will have the form close to that shown in Figure 7.

The above studies made it possible to design and to manufacture a high-torque inductor-type electric motor intended for operation as a part of a controlled electric drive. The criterion of optimality in the calculation was proposed the function $M / P \rightarrow \max$, where $P$ is the electrical losses in the windings. The constraints were the dimensions of the electric machine. Below there are the main parameters of a built-in RD (without shaft and bearing assemblies):

1. Rated torque - $7.5 \mathrm{Nm}$;

2. Outer diameter - $100 \mathrm{~mm}$;

3. Maximum length - $57 \mathrm{~mm}$;

4. Electrical losses - $48 \mathrm{~W}$;

5. Weight - $1.28 \mathrm{~kg}$;

6. Own speed - $20000 \mathrm{rad} / \mathrm{sec}^{2}$. 


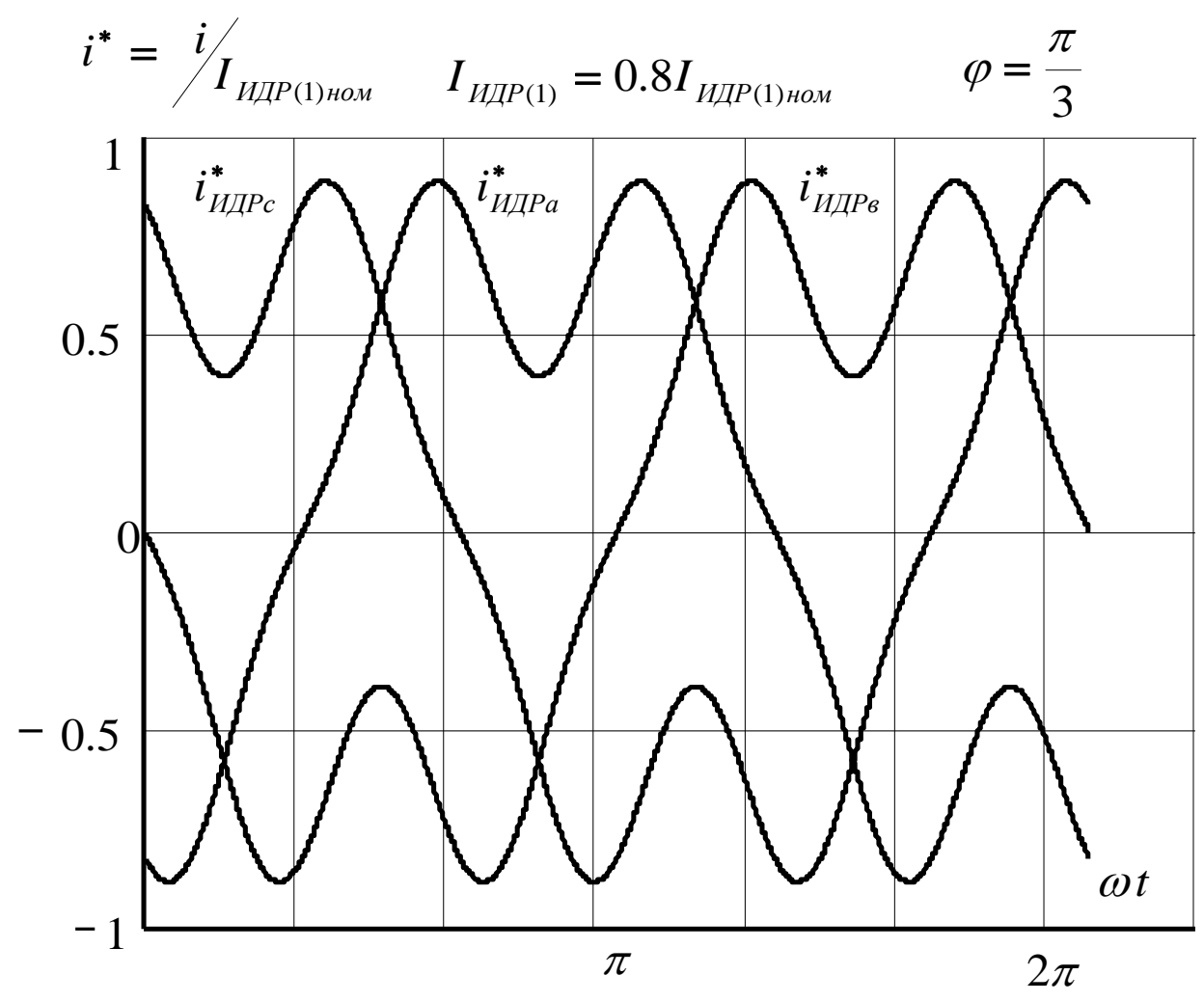

Figure 7. The shape of the resulting current in the motor phases

The forced formation of the third and fifth time harmonics, alongside with organization of a no-current pause near the point of transition of the function $i(t)$ through zero (about 60 degrees), made it possible at the same current amplitude to increase the torque by $37 \%$ with simultaneous decreasing of losses by $18 \%$.

\section{Analysis}

When analyzing the models shown in Figures 3, 4, the following conclusions can be drawn:

1. Rotating waves of MMF and magnetic conductivity $\lambda(\theta, \alpha)$ in Figure 3 are replaced by pulsating waves acting within each phase in Figure 3 . At this, the spatial and time characteristics $F(\alpha, t)$ and $\lambda(\theta, \alpha)$ within each large tooth remain unchanged.

2. The electrical machine shown in Figure 4 has all the disadvantages of a two-phase stepper motor and undoubtedly loses in its technical characteristics to the motor shown in Figure 3, but in the linear formulation of the problem it turns out to be identical to it.

The equations for own and mutual inductances for the mathematical model (Figure 4) are similar to those derived earlier in [47].

To derive the equations of stress and moment, we will use the modified Rademacher functions, the basic concepts of which, as well as the methods of calculating inductances with their help, are set forth in [50]. After carrying out the necessary mathematical operations, the expressions for own and mutual (with respect to the "excitation winding") inductances will be obtained in the following form: 


$$
\begin{gathered}
L_{0}=\frac{\mu_{0} \pi D_{a} L_{a} w_{1}^{2}}{2 m \delta k_{\delta}} \\
L_{k 0}=\frac{\mu_{0} \beta \pi D_{a} L_{a} w_{1} w_{0}}{2 m \delta k_{\delta}}\left[\cos z_{2} \theta-\frac{2 \pi}{m}(k-1)\right]
\end{gathered}
$$

Here: $\mathrm{m}=3,5,7 \ldots$ is the number of phases; $\mathrm{k}=1,2,3, \ldots$ is a positive integer.

Having performed transformations using the method of symmetric components and assuming for the steady-state mode of operation that the operator $p$ is equal to zero, and $z_{2} \omega_{p}=\omega_{1}$, we obtain:

$$
\begin{aligned}
& \dot{U}_{+}=r_{1} \dot{I}_{+}+j \omega_{1} L_{0} \dot{I}_{+}+j \omega_{1} \frac{\sqrt{m}}{2} i_{r} \beta L_{0} \times e^{j \theta_{n}} ; \\
& \dot{U}_{-}=r_{1} \dot{I}_{-}-j \omega_{1} L_{0} \dot{I}_{-}-j \omega_{1} \frac{\sqrt{m}}{2} i_{r} \beta L_{0} \times e^{-j \theta_{n}} ; \\
& U_{f 0}=r_{f 0} \times i_{r} . \\
& M=\frac{\sqrt{m}}{2} z_{2} \beta L_{0} i_{r}\left[-j \dot{I}_{+} e^{j \theta_{n}}+j \dot{I}_{-} e^{-j \theta_{n}}\right]=\frac{z_{2} m U_{m} i_{r} \beta L_{0}\left(r_{1} \sin \theta_{u}-\omega_{1} L_{0} \cos \theta_{u}\right)}{2\left[r_{1}^{2}+\left(\omega_{1} L_{0}\right)^{2}\right]} .
\end{aligned}
$$

Expressions (13), (15) are derived for the case when instead of permanent magnets, a winding with the $w_{0}$ number of turns develops a radial excitation flux. If the machine uses magnets, then flux linkage is considered as $\psi_{m}=\beta L_{0} i_{r}$.

\section{Results}

The above studies made it possible to design and to manufacture a high-torque inductor-type electric motor intended for operation as part of shut-off valves (Figure 8). The $M / P \rightarrow \max$ function was proposed as the optimality criterion in the calculation, where $P$ is the electrical losses in the windings, and the constraints are the dimensions of the electric machine.

This study can be developed in the direction of simplifying the circuit, which will provide a minimum number of elements. This will lead to the use of the maximum torque, and the solution will be to bring the control system with a circuit on the limit switches.

Below there are the main parameters of the electric mechanism that includes an inductor motor and a planetary mechanical transmission:

1. Rated torque - $32 \mathrm{Nm}$;

2. Maximum torque - $64 \mathrm{Nm}$;

3. Nominal electrical losses $-35 \mathrm{~W}$;

4. Maximum electrical losses at start-up - $350 \mathrm{~W}$;

5. Maximum power consumption - $600 \mathrm{~W}$;

6. Rated frequency of rotation of the output shaft of the engine - $60 \mathrm{rpm}$; 
7. Maximum rotational speed of the engine output shaft - $130 \mathrm{rpm}$;

8. Outside length of the electric mechanism - $100 \mathrm{~mm}$;

9. The outer diameter of the electric mechanism - $126 \mathrm{~mm}$;

10. Gear ratio - 4.95;

11. Total weight $-4.3 \mathrm{~kg}$.

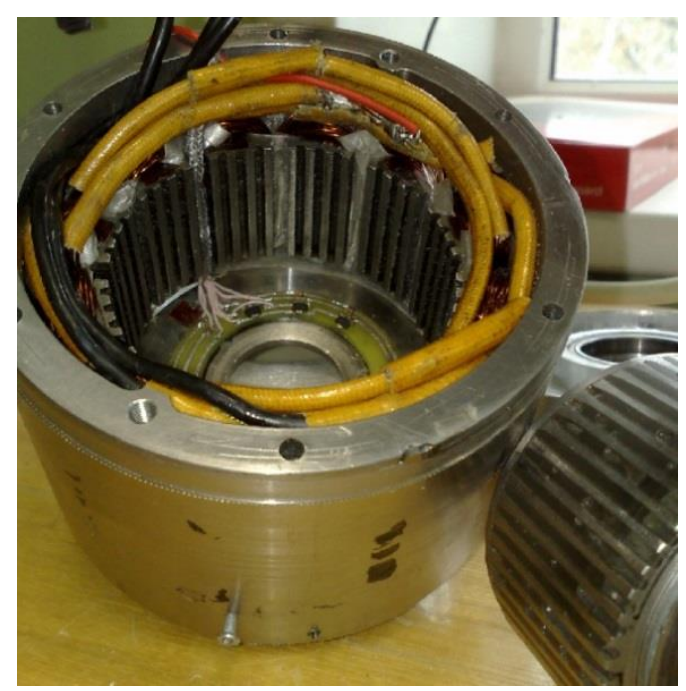

Figure 8. A high-torque inductor-type electric motor

Author Contributions: Conceptualization, D.K. and N.U.; methodology, D.K.; validation, A.U.; formal analysis, N.U.; resources, A. U.; writing-original draft preparation, D.K. and A.M.; writing - review and editing, A.U. and A.M.; supervision, D.K.; project administration, D.K. All authors have read and agreed to the published version of the manuscript.

Funding: This research was funded by grant of the Russian Federation President according to the research project No. MK-2204.2020.8.

Institutional Review Board Statement: Not applicable.

Informed Consent Statement: Not applicable.

Data Availability Statement: The data presented in this study are available on request from the corresponding author. The data are not publicly available due to privacy issues.

Conflicts of Interest: The authors declare no conflict of interest.

\section{References}

1. D. Krušelja, D Sumina. Modified predictive torque control method of induction machines for torque ripple reduction. AUTOMATIKA 2019, VOL. 60, NO. 2, 227-238 doi.org/10.1080/00051144.2019.1614345

2. Nash JN. Direct torque control, induction motor vector control without an encoder. IEEE Trans Industry Appl. 1997;33(2):333341.

3. Casadei D, Profumo F, Serra G. FOC and DTC: two viable schemes for induction motors torque control. IEEE Trans Power Electron. 2002;17(5):779-787.

4. Depenbrock M. Direkte Selbstregelung (DSR) für hochdynamische Drehfeldantriebe mit Stromrichter-speisung. Etz Archiv. 1985;7:211-218.

5. Depenbrock M. Direct self-control (DSC) of inverterfed induction machine. IEEE Trans Power Electron.1988;3(4):420-429.

6. Takahashi I, Noguchi T. A new quick-response and high-efficiency control strategy of an induction motor. IEEE Trans Industry Appl. 1986; IA-22(5):820-827.

7. Tiitinen P, Pohjalainen P, Lalu J. The next generation motor control method: direct torque control (DTC). Eur Power Electr Drives J. 1995;5(1):14-18.

8. Sutikno T, Idris NRN. A review of direct torque control of induction motors for sustainable reliability and energy efficient drives. ELSEVIER Renew Sustain Energ. Rev. 2014; 32:548-558. 
9. Kumar RH, Iqbal A, Lenin NC. Review of recent advancements of direct torque control in induction motor drives - a decade of progress. IET Power Electr. 2018;11(1):1-15.

10. Cortés P, Kazmierkowski MP, Kennel RM, et al. Predictive control in power electronics and drives. IEEE Trans Ind Electron. 2008;55(12):4312-4324.

11. Kuoro S, Cortés P, Vargas R, et al. Model predictive control-a simple and powerful method to control power converters. IEEE Trans Ind Electron. 2009;56(6):1826-1838.

12. Bariša T, Ileš Š, Sumina D, et al. Model predictive direct current control of a permanent magnet synchronous generator based on Flexible Lyapunov function considering converter dead time. IEEE Trans Industry Appl. 2018;54(3):2899-2912.

13. Kuoro S, Perez M, Rodríguez J, Llor A, Young H. Model predictive control: MPC's Role in the Evolution of power electronics. IEEE Ind Electron Mag. 2015;9(Dec):8-21.

14. Vazquez S, Rodríguez J, Rivera M, et al. Model predictive control for power converters and drives: advances and Trends. IEEE Trans Ind Electron. 2017;64(2): 935-947.

15. Wang F, Davari SA, Chen Z, et al. Finite control set model predictive control of induction machine with a robust adaptive observer. IEEE Trans Ind Electron. 2017;64(4):2631-2641.

16. Zhang Y, Yang H. Two-vector-based model predictive torque control without weighting factors for induction motor drives. IEEE Trans Power Electron. 2016;31(2):381-1390.

17. Nikzad MR, Asaei B, Ahmadi SO. Discrete dutycycle-control method for direct torque control of induction motor drives with model predictive solution. IEEE Trans Power Electron. 2018;33(3):2317-2329.

18. Cortés P, Kuoro S, La Rocca B, Vargas R, Rodríguez J, Leon JI, Vazquez S, Franquelo LG. Guidelines for weighting factors adjustment in finite state model predictive control of power converters and drives. 2009 Proceedings of the IEEE Conference Industrial Technology; 2009 Feb 10-13; Gippsland, Australia; 2009. p. 1-7.

19. A. Sabir, S. Ibrir. Induction motor speed control using reduced-order model. AUTOMATIKA 2018, VOL. 59, NOS. 3-4, $274-285$. doi.org/10.1080/00051144.2018.1531963

20. Fekih A, Chowdhury FN. On nonlinear control of induction motors: comparison of two approaches. American Control Conference. Vol. 1; 2004. p. 1135-1140.

21. Barambones O, Alkorta P. Vector control for induction motor drives based on adaptive variable structure control algorithm. Asian J Control. 2010;12(5): 640-649.

22. Retiere N, Foggia A, Roye D, et al. Deep-bar induction motor model for large transient analysis under saturated conditions. 1997 IEEE International Electric Machines and Drives Conference Record; IEEE; 1997. p. MD1/3.1-MD1/3.3.

23. Li Binga, Liu Shib, Long Teng. Duty ratio modulation direct torque control of brushless doubly-fed machines. AUTOMATIKA, 2017. VOL. 58, NO. 4, 479-486. doi.org/10.1080/00051144.2017.1343421

24. Domenico Casadei FGAA. FOC and DTC: two viable schemes for induction motors torque control. IEEE Trans Power Electron. 2002;17(5):779-787.

25. T. Jerčić, Š. Ileš, D. Žarko. Constrained field-oriented control of permanent magnet synchronous machine with field-weakening utilizing a reference governor. AUTOMATIKA, 2017. VOL. 58, NO. 4, 439-449. doi.org/10.1080/00051144.2018.1453441

26. Lee J, Nam K, Choi S, et al. A lookup table based loss minimizing control for FCEV permanent magnet synchronous motors. Vehicle Power and Propulsion Conference, 2007; VPPC 2007; IEEE; 2007. p. 175-179.

27. Jung S.Y., Hong J, Nam K. Current minimizing torque control of the IPMSM using Ferrari's method. IEEE Trans Power Electron. 2013;28(12):5603-5617.

28. Cao M. Online loss minimization control of IPMSM for electric scooters. Power Electronics Conference (IPEC), 2010 International. IEEE; 2010. p. 1388-1392.

29. Uddin MN, Zou H, Azevedo F. Online loss-minimization-based adaptive flux observer for direct torque and flux control of PMSM drive. IEEE Trans Ind Appl. 2016;52(1):425-431.

30. P. Ćalasan. An invertible dependence of the speed and time of the induction machine during no-load direct start-up. AUTOMATIKA. 2020, VOL. 61, NO. 1, 141-149 doi.org/10.1080/00051144.2019.1689725.

31. Aree P. Precise analytical formula for starting time calculation of medium- and high-voltage induction motors under conventional starter methods. Electr Eng Archiv fur Electron. 2018;100(2):1195-1203.

32. Calasan M. Analytical solution for no-load induction machine speed calculation during direct start-up. Int Trans Electr Energy Syst. 2019;29(4):e2777.

33. Solveson M.G., Mirafzal B, Demerdash NAO. Soft-started induction motor modeling and heating issues for different starting profiles using a flux linkage ABC frame of reference. IEEE Trans Ind Appl. 2006;42(4):973-982.

34. Badr MA, Abdel-Halim M.A., Alolah A.I. A nonconven-tional method for fast starting of three phase wound-rotor induction motors. IEEE Trans Energy Conv.1996;11(4):701-707.

35. Pillary K, Nour M, Yang K.H., et al. Assessment and comparison of conventional motor starters and modern power electronic drives for induction motor starting characteristics. IEEE Symp Ind Electron Appl. 2009;584-589.

36. Z. Cevrovský, M. Lev. Permanent Magnet Synchronous Machine Parameters Identification for Load Characteristics Calculation. AUTOMATIKA 56(2015) 2, 217-225. DOI 10.7305/automatika.2015.07.813

37. Official site of the Closed Joint Stock Company "Energomash" (Chekhov, RF) - www.zavodchzem.ru

38. Calabrese, D.; Tricarico, G.; Brescia, E.; Cascella, G.L.; Monopoli, V.G.; Cupertino, F. Variable Structure Control of a Small Ducted Wind Turbine in the Whole Wind Speed Range Using a Luenberger Observer. Energies 2020, $13,4647$. https://doi.org/10.3390/en13184647 
39. E. Brescia, M. Palmieri, G. L. Cascella and F. Cupertino, "Optimal Tooth Tips Design for Cogging Torque Suppression of Permanent Magnet Machines with a Segmented Stator Core," 2020 International Conference on Electrical Machines (ICEM), Gothenburg, Sweden, 2020, pp. 1930-1936, doi: 10.1109/ICEM49940.2020.9270968

40. Brescia, E.; Costantino, D.; Massenio, P.R.; Monopoli, V.G.; Cupertino, F.; Cascella, G.L. A Design Method for the Cogging Torque Minimization of Permanent Magnet Machines with a Segmented Stator Core Based on ANN Surrogate Models. Energies 2021, 14, 1880. https://doi.org/10.3390/en14071880

41. Antonov A.S., Artamonov B.A., Korobkov B.M. Planetary gears // Tank. - M .: Military Publishing, 1954, p. 422 - 607.

42. O. N. Veselovsky, D.L. Kalushski. Equations of electrical equilibrium and torque of synchronous and asynchronous motors with discretely distributed windings. Electricity, No. 5, 2000, p. 31 - 36.

43. D. L. Kalushski, A.M. Strizhkov, A.T. Galimzyanov. Comparative analysis of high-torque engines. On Sat. scientific. works of the city of Yekaterinburg, FGAOU VPO UrFu named after B, N. Yeltsin 2011.329 p.

44. A.C. No. 1481875 USSR. Synchronous electric motor. / Zhulovyan V.V., Geraskina N.M., Kalushski D.L., Novikov P.A., Markov Yu.L., Kutuzov E.I. - Bul. No. 19, 1989.

45. Electric machine. Japan Patent No. 61 -14743. Applicant Matsushita denki sangyo, 1989.

46. D. L. Kalushski, O. N. Veselovski. Permanent magnet inductor motor. On Sat. reports of the International conference UEES. St. - Petersburg, V. 1, 2004, p. 92 - 98.

47. D. L. Kalushski, A.M. Strizhkov, S.A. Kharitonov. Equations of electrical equilibrium and torque of a reactive inductor motor. Electricity, No. 5, 2010, p. 43 - 48.

48. D. L. Kalushski. Electric machines with discretely distributed windings. Electrical Engineering, No. 9, 1997 , p. 5.

49. Permanent magnet synchronous inductor motor/ D.L. Kalushski, V.V. Shepherds, Ponds. N.M. Utility model patent No. 125414 dated 05.06.12.

50. D. L. Kalushski, A.M. Strizhkov, A.T. Galimzyanov. Equations of electrical equilibrium and torque of a two-phase inductor motor. Electricity, No. 8, 2010, p. 59 - 63. 